\title{
Efficient increase of the novel recombinant human plasminogen activator expression level and stability through the use of homozygote transgenic rabbits
}

\author{
ZHENGYI HE ${ }^{1-3}$, LEI JIANG ${ }^{1-3}$, TING ZHANG ${ }^{1-3}$, MINYA ZHOU ${ }^{1-3}$, DAIJIN WU ${ }^{1-3}$, \\ TINGTING YUAN $^{4}$, YUGUO YUAN ${ }^{1-3}$ and YONG CHENG ${ }^{1-3}$ \\ ${ }^{1}$ College of Veterinary Medicine, Yangzhou University; ${ }^{2}$ Engineering Research Centre for \\ Transgenic Animal Pharmaceutics in Jiangsu Province; ${ }^{3}$ Jiangsu Co-innovation Center for Prevention \\ and Control of Important Animal Infectious Diseases and Zoonoses; ${ }^{4}$ Medical College of \\ Yangzhou University, Yangzhou, Jiangsu 225009, P.R. China
}

Received November 6, 2017; Accepted June 19, 2018

DOI: $10.3892 /$ ijmm.2018.3754

\begin{abstract}
Expression efficacy of recombinant protein in current expression systems is generally low. Therefore, the expression levels of recombinant proteins in the breast milk of transgenic animals are typically low. In view of this, the present study aimed to construct homozygous transgenic rabbits with a high expression level of recombinant human plasminogen activator (rhPA) during the entire lactation period. Homozygous transgenic rabbits were obtained using an effective rhPA mammary-specific expression vector PCL25/rhPA. The expression level and thrombolytic ability of rhPA in the milk of both homozygous and hemizygous rabbits were detected by enzyme-linked immunosorbent and fibrin agarose plate assays. It was observed that the expression of rhPA was constant during the entire lactation period in homozygous rabbits, while the expression of rhPA declined slowly in hemizygote rhPA transgenic rabbits during the lactation period. In addition, the expression of rhPA in homozygous transgenic rabbit was $\sim 950 \mu \mathrm{g} / \mathrm{ml}$, which was markedly higher in comparison with that in hemizygote rabbits. Furthermore, increased gene copy number was observed to increase the expression level of rhPA at the same integration vector.
\end{abstract}

\section{Introduction}

Recombinant proteins are the main biopharmaceutical agents (1-4), and the reduction of primary cost of recombinant proteins and improvement of their quality by selecting novel

Correspondence to: Dr Yong Cheng, College of Veterinary Medicine, Yangzhou University, 48 Wenhui Road, Yangzhou, Jiangsu 225009, P.R. China

E-mail: chengyong@yzu.edu.cn

Key words: thrombotic diseases, human tissue-type plasminogen activator, recombinant human plasminogen activator, mammary gland bioreactor, expression stability efficient expression systems has received increasing attention (1-4). The production of recombinant proteins through the use of bacterial hosts, mammalian cells, yeast, viruses, transgenic plants or other expression systems has numerous disadvantages, including poor biological activity, high cost and poor protein post-translation modification among other (1-4). Recombinant proteins expressed in the mammary gland of transgenic animals have become a research focus as bioreactors due to their high expression, low cost, easy purification process and similar protein modification to that in the human body (4-11). Therefore, the animal mammary gland is currently the most ideal expression system for the production of recombinant proteins. Various recombinant proteins, such as ATryn, hAAT, recombinant human protein $\mathrm{C}$, superoxide dismutase (SOD) and hormones, have been generated in the milk of transgenic animals (8-12). However, although the first production of recombinant proteins through the milk of transgenic animal for therapeutic use was reported 30 years ago, the recombinant proteins expression regulatory mechanism in the milk of these animals remains unclear and only a few recombinant proteins have been successfully produced through the transgenic animal mammary gland $(4,13)$.

The expression of recombinant proteins in the mammary gland of transgenic animals is a complex process affected by various factors, including the genetic structure, gene copy number and their regulatory elements, gene integration site, promoter and methylation $(3,4)$. At present, the expression level and stability of recombinant proteins in transgenic animals are not sufficient to allow for larger-scale production of the desired proteins $(3,4)$.

Thrombotic diseases are serious threat to human health, and thrombolytic agents are the main drugs used in the treatment of these diseases (14-19). The human tissue-type plasminogen activator (tPA) is a key kinase of fibrinolysis that serves an important role in dissolving fibrin clots to promote thrombolysis $(16,17)$. To increase the half-life and thrombolytic activity of tPA, a mutant of tPA containing only the essential $\mathrm{K} 2$ fibrin-binding and $\mathrm{P}$ activating plasminogen domains of the wild-type tPA transgenic rabbit has been generated (19). 
Recombinant human plasminogen activator (rhPA) is a novel drug for the treatment of thrombolytic disease (19). Compared with the natural human tPA, rhPA has higher thrombolytic activity and some other advantages, such as a high affinity to fibrin, low incidence of side effects of systemic bleeding, long half-life in the blood and low total dose (18-23). Therefore, as a representative of the third-generation thrombolytic agents, rhPA has been increasingly accepted by the majorities of patients (23).

Currently, there are no studies reporting the difference in rhPA expression in the milk of homozygous and hemizygous rhPA transgenic rabbits. Compared with other animals, homozygous transgenic rabbits present numerous advantages, including genetic stability, no need for PCR integrate testing on offspring and reduced detection cost. In addition, all animals can have the same genotype and an excellent reproductive rate (24-27).

The objective of the present study was to improve the expression and stability of mammary gland-specific rhPA in homozygote transgenic rabbits. Enzyme-linked immunosorbent assay (ELISA) and fibrin agarose plate assay (FAPA) were used to analyze the rhPA expression level and stability in the milk of the homozygous transgenic rabbits, as previously described (28-31). The results indicated that rhPA expression in homozygous transgenic rabbit was markedly higher in comparison with that in hemizygous transgenic rabbits. Thus, transgenic rabbits with high rhPA expression and stability were obtained. A new strain (K29) of rhPA transgenic rabbits was established in the current study, and two homozygous transgenic rabbits (K29 F2-05 and K29 F2-09) were obtained. With those efforts, the current study aimed to increase the novel rhPA expression level and stability.

\section{Materials and methods}

Animals and reagents. The present study was approved by the Institutional Animal Care and Use Committee of Yangzhou University (Yangzhou, China) and was performed according to the Guide for the Care and Use of Laboratory Animals (32). A total of 30 female New Zealand rabbits (2.5-3.0 kg, 210 days old, Better Biotechnology Co., Ltd., Nanjing, China) used in the current study were raised at room temperature $\left(25 \pm 2^{\circ} \mathrm{C}\right)$ under specific-pathogen-free conditions, and allowed free access to food and water. All chemicals were purchased from Sigma-Aldrich (Merck KGaA, Darmstadt, Germany) unless otherwise specified. The rhPA transgenic rabbits were generated in our lab, as previously described $(5,6)$.

Construction of mammary gland-specific rhPA gene expression vector. The rhPA mammary gland-specific expression vector in rabbits was constructed in our lab. It included the effective mammary-specific expression vector PCL25/rhPA (F,E,K1 domains deletion mutant of tPA) and goat $\beta$-casein gene as regulatory elements. Subsequently, rhPA transgenic rabbits were generated through microinjection into rabbit's fertilized eggs with vector concentration at $5 \mathrm{ng} / \mu \mathrm{l}(5)$.

Generation of homozygote transgenic rabbits. Male rhPA transgenic rabbits K29 were selected as the F0 rabbits, and they were mated with normal nontransgenic rabbits in order to obtain the F1 transgenic rabbits, and F1 male and female rabbits were then mated to obtain the $\mathrm{F} 2$ transgenic rabbits. Next, the F2 transgenic rabbits were mated with normal nontransgenic rabbits to obtain $\mathrm{F} 3$ rabbits as a test cross. Homozygous transgenic rabbits were then screened out from the F2 generation through F2 rabbit test cross and polymerase chain reaction $(\mathrm{PCR})$ according to the methods described in a previous study (5). All the rhPA-positive rabbits were identified through the PCR method. After the F2 generation rabbit mating with normal nontransgenic rabbits, F2 rabbits were consider as homozygous ( $>99.9 \%$ ) if their descendants were $>5$ and if all rabbits were positive for rhPA $(24,25)$.

PCR test. Genomic DNA was extracted from rabbits with the phenol-chloroform method. Transgenic rabbits were identified with PCR analysis using the extracted genomic DNA. The upstream primer was located on the promoter region, while the downstream primer was located on the rhPA coding region. The amplification production size was 566 bp at the CMV and rhPA joint area. Primers were designed with the Primer Premier software (version 5.0; Premier Biosoft, Palo Alto, CA, USA), and the primer sequences were (5,30): Forward, 5'-CGTGGA TAGCGGTTTGA-3', and reverse, 5'-GAGCCCTCCTTTGAT GC-3'. PCR reaction conditions were: $95^{\circ} \mathrm{C}$ for $5 \mathrm{~min}$, followed by 30 cycles of $94^{\circ} \mathrm{C}$ for $45 \mathrm{sec}, 55^{\circ} \mathrm{C}$ for $45 \mathrm{sec}$, and $72^{\circ} \mathrm{C}$ for $1 \mathrm{~min}$ for a total of 30 cycles, and then $72^{\circ} \mathrm{C}$ for $10 \mathrm{~min}$. PCR Master Mix (Thermo Fisher Scientific) was used to prepare PCR reaction system, and PCR product was confirmed by agarose gel electrophoresis (1.1\% gel) and gel images were analyzed using a Digital Gel Imaging Analysis system (GIS-1000, Shanghai Tianneng Technology Co., Ltd., Shanghai, China).

Pretreatment of transgenic rabbit milk. Rabbit milk was collected everyday during the lactation period (4 weeks after kindling), followed by centrifugation at $4,000 \times \mathrm{g}, 4^{\circ} \mathrm{C}$ for $30 \mathrm{~min}$, precipitation was removed and the fat in the top layer was also removed. The rabbit whey was collected and the $\mathrm{pH}$ value was adjusted to 2.5 with $50 \%$ phosphoric acid and $0.5 \mathrm{~mol} / 1 \mathrm{HCl}$. Next, the milk was centrifuged at $6,000 \mathrm{x} \mathrm{g}$ at $4^{\circ} \mathrm{C}$ for $30 \mathrm{~min}$, the supernatant was collected and the $\mathrm{pH}$ value was adjusted to 3.5 with $1 \mathrm{~mol} / \mathrm{l}$ sodium hydroxide (50\%). A total of 5 centrifugation cycles were performed at $6,000 \mathrm{xg}$ at $4^{\circ} \mathrm{C}$ for $10 \mathrm{~min}$, the supernatant was collected after each centrifugation, and $1 \mathrm{~mol} / \mathrm{l}$ sodium hydroxide was added to adjust the $\mathrm{pH}$ value to $4.5,5.5,6.5,7.5$ and 8.5 after collections of supernatant, respectively, at each successive cycle $(6,33,34)$. Finally, the supernatant was filtered with a $0.22-\mu \mathrm{m}$ aperture membrane filter to remove any impurities.

Determination of rhPA in transgenic rabbit milk by ELISA. Indirect ELISA was used to determine the rhPA level in the milk of transgenic rabbits $(29,35,36)$. ELISA kits (cat. no. QY-H11759) were purchased from Westang Biotechnology Co., Ltd (Shanghai, China) and the analysis was conducted according to the manufacturer's protocol. Briefly, $100 \mathrm{ul}$ of rhPA transgenic rabbit milk whey was immobilized to each well of ELISA plate (96-well) by physical adsorption as the detecting antigen. The well containing thrombolytic drug alteplase (Sigma-Aldrich; Merck KGaA) was used as the positive control, while the normal nontransgenic rabbit milk whey was used as the control antigen to exclude the false positive 


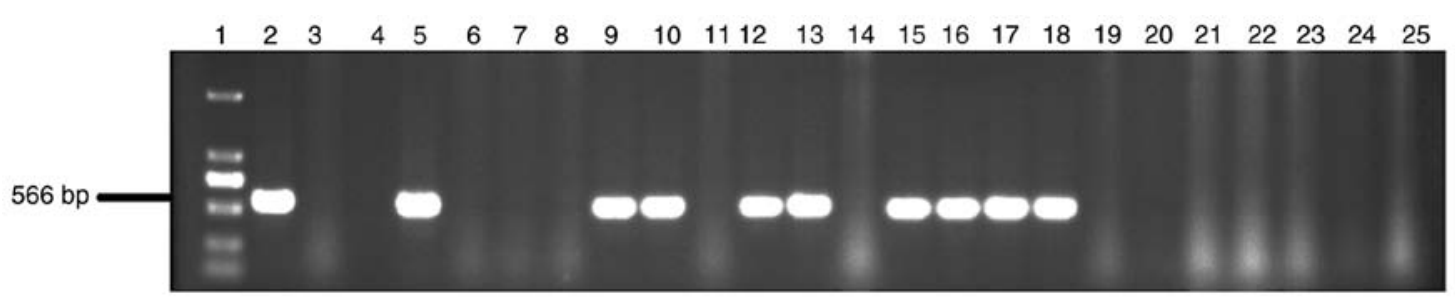

Figure 1. Lanes 1, DL2000 DNA marker ladder; 2, PCR amplification products of rhPA gene microinjection serving as the positive control; 3, double-distilled water as the blank; 4, PCR amplification products of F0 transgenic rabbits serving as the positive control; 5-21, PCR amplification products of the offspring of homozygote transgenic rabbits mated with normal nontransgenic rabbits.

results. PBS (containing $137 \mathrm{mM} \mathrm{NaCl}, 10 \mathrm{mM} \mathrm{Na}_{2} \mathrm{HPO}_{4}$ $3 \mathrm{mM} \mathrm{KCl}$ and $2 \mathrm{mM} \mathrm{KH}_{2} \mathrm{PO}_{4}, \mathrm{pH}$ 7.4) was used as the blank control. Following thorough washing using washing solution in the ELISA kit, the sample was mixed with the chromogenic substrate tetramethyl benzidine. The intensity of the staining color and the rhPA level in the samples were positively correlated. Absorbance (optical density) was examined at $450 \mathrm{~nm}$, and the concentrations of rhPA in the samples were calculated according to the instructions of the ELISA kit. Briefly, following incubation in blocking solution at $37^{\circ} \mathrm{C}$ for 1.5 hours, washing was performed with washing solution 3 times, for 5 min each time. The primary rhPA Monoclonal antibodies (1:4,000; cat. no. sc-59721; Santa Cruz Biotechnology, Inc., Dallas, TX, USA) was added and incubated at $37^{\circ} \mathrm{C}$ for $1.5 \mathrm{~h}$, then washed with washing solution 3 times, 5 min each time. Then secondary horseradish peroxidase-conjugated goat anti-mouse Immunoglobulin G (1:4,000; cat. no. sc-2005; Santa Cruz Biotechnology, Inc.) was added and incubated at $37^{\circ} \mathrm{C}$ for $1.5 \mathrm{~h}$. Analysis was performed using a microplate reader with the internal software (RT-6000; Rayto Life and Analytical Sciences Co., Ltd., Shenzen, China).

Detection of thrombolytic activity of transgenic rabbit milk by FAPA. The thrombolytic bioactivity of rhPA transgenic rabbit milk was evaluated in vitro through FAPA using a fibrin-thrombin-agarose gel containing $1.0 \%$ (w/v) agarose, $10 \mathrm{mg} / \mathrm{ml}$ fibrinogen containing a small amount of plasminogen, and $1 \mathrm{U} / \mathrm{ml}$ thrombin in PBS (31,35-37). The rhPA transgenic rabbit whey samples were diluted for analysis using PBS. In order to obtain the fibrin-thrombin-agarose gel, PBS was used as a solvent and mixed with $1.0 \%$ agarose gel, $10 \mathrm{mg} / \mathrm{ml}$ fibrinogen and $1 \mathrm{U} / \mathrm{ml}$ thrombin. Next, $15 \mathrm{ml}$ agarose gel was boiled. When the temperature dropped to $55-60^{\circ} \mathrm{C}$, $1 \mathrm{ml}$ fibrinogen $37^{\circ} \mathrm{C}$ was preheated, and thrombin was heated to $42^{\circ} \mathrm{C}$, then agarose gel, fibrinogen and thrombin were immediately mixed and transferred to a glass dish. When the solution cooled to room temperature, fibrin-thrombin-agarose solidified to a gel state. Sample wells were drilled in each gel, and each sample well filled with $20 \mu \mathrm{l}$ sample solution, followed by incubation at $37^{\circ} \mathrm{C}$ for $24 \mathrm{~h}$. The thrombolytic activity of each sample was determined based on the diameter size of the thrombin-dissolving ring.

Evaluation of rhPA expression in transgenic rabbit milk by western blot analyses. Protein concentration was measured using a bicinchoninic acid assay. Western blot analysis was used to detect the expression of rhPA in the transgenic rabbit milk, as previously described (6,29,35-37). Briefly, whey samples were denatured in boiling water $\left(100^{\circ} \mathrm{C}\right)$ for $5 \mathrm{~min}$. The protein bands were then separated under denaturing conditions by 12\% SDS-PAGE using Mini-Protean II Electrophoresis Cell (Bio-Rad Laboratories, Inc., Hercules, CA, USA). Next, the unstained proteins were electrotransferred, to a polyvinylidene difluoride membrane. Following transfer, the membrane was blocked with $5 \%(\mathrm{v} / \mathrm{v})$ skimmed milk containing $0.1 \%$ Tween 20 for $90 \mathrm{~min}$ at $42^{\circ} \mathrm{C}$, and the membrane was then probed overnight at $4^{\circ} \mathrm{C}$ in the same buffer containing a mouse anti-human rhPA primary antibody (1:2,000 dilution; sc-59721; Santa Cruz Biotechnology, Inc.). Subsequently, the membrane was incubated with the secondary antibody conjugated with horseradish peroxidase (cat. no. A01854-200; 1:1,000; GenScript, Piscataway, NJ, USA) for $2 \mathrm{~h}$ at $37^{\circ} \mathrm{C}$. Finally, the membrane was washed three times with the wash buffer, and the reaction was developed with $\mathrm{DAB}$ colorimetric solution reagent.

\section{Results}

Generation of homozygous rhPA transgenic rabbits. Transgenic rabbits K29 were selected to mate with normal female New Zealand rabbits. A total of $25 \mathrm{~F} 1$ offspring rabbits were obtained, and 16 of these were found to be transgenic rabbits using the PCR method. F1 male transgenic rabbits were then mated with female F1 transgenic rabbits to obtain F2 transgenic rabbits. A total of $10 \mathrm{~F} 2$ offspring rabbits were obtained, and it was observed that $5 \mathrm{~F} 2$ rabbits (4 female and 1 male) were transgenic. Finally, F3 rabbits were obtained by mating F2 transgenic rabbits with normal rabbits. PCR was used to analyze the genomic DNA of the F3 rabbits, and homozygous rhPA transgenic rabbits were screened out from the F2 generation of transgenic rabbits through a test cross. F3 generation rabbits were subjected to DNA extraction, followed by PCR reaction and gel electrophoresis. All the 16 rabbits from the F3 generation were identified to be transgenic and the results demonstrated that 2 F2 transgenic rabbits (K29 F2-05 and K29 F2-09) were homozygous (Figs. 1 and 2).

Evaluation of rhPA expression level in the milk of homozygous transgenic rabbits by ELISA. ELISA was used to analyze the rhPA expression level in the milk of transgenic rabbits. As shown in Figs. 3 and 4, ELISA results revealed that rhPA expression in the milk of homozygous K29 strain transgenic rabbits was approximately two times higher in comparison with that in the hemizygote K29 strain transgenic rabbits. Notably, the rhPA expression level in the milk of homozygous rabbits was stable $(\sim 0.95 \mathrm{mg} / \mathrm{ml})$ throughout the entire lactation period. However, the rhPA expression level in hemizygous 


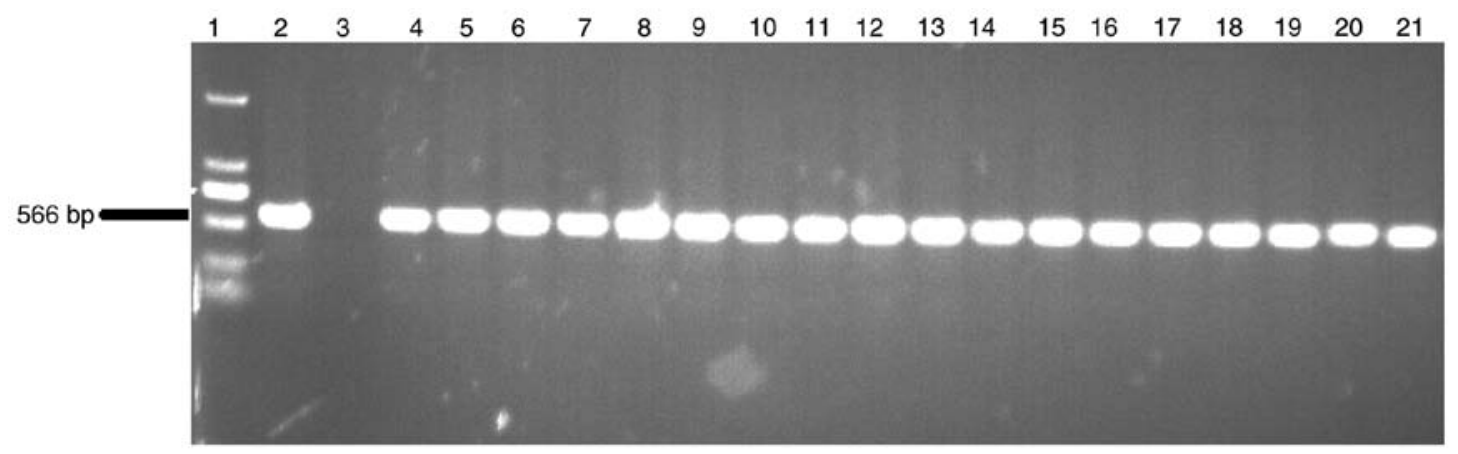

Figure 2. Lanes 1, DL2000 DNA marker ladder; 2, PCR amplification products of rhPA gene microinjection serving as the positive control; 3, PCR amplification products of normal nontransgenic rabbits serving as the negative control; 4, double-distilled water as the blank; 5-25, PCR amplification products of the offspring of homozygote transgenic rabbits mated with normal nontransgenic rabbits.

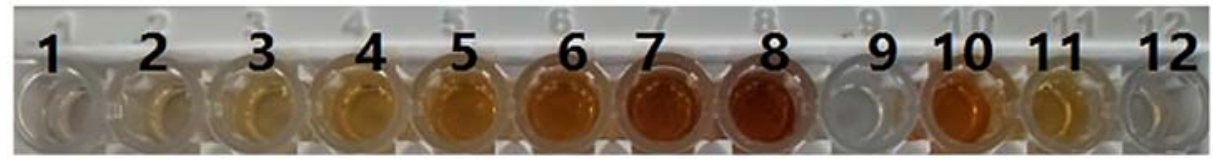

Figure 3. Enzyme-linked immunosorbent assay of partial transgenic rabbit whey. Sample 1, PBS; samples 2-8, alteplase serving as the injection standard at concentrations of 5, 10,50,500,1,000,2,000 and 4,000 ng/ml, respectively; sample 9, whey from normal nontransgenic rabbits; sample 10, whey from homozygote K29 transgenic rabbits (diluted to 1,000-fold); sample 11, whey obtained on days 1-5 from hemizygote K29 transgenic rabbits (diluted to 1,000-fold); sample 12, whey obtained on days 6-30 from hemizygote K29 transgenic rabbits (diluted to 1,000-fold).
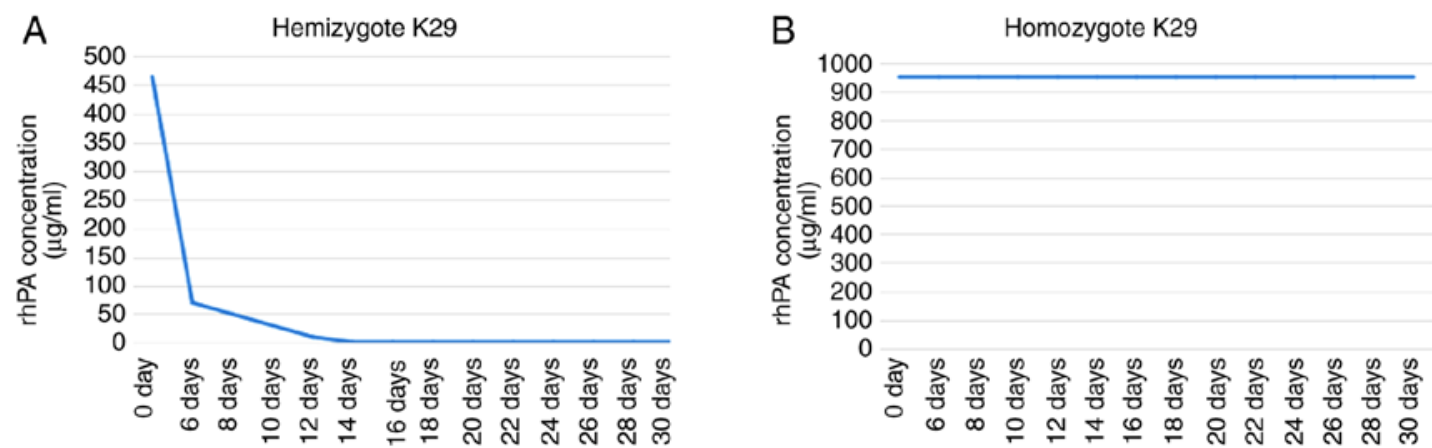

Figure 4. Detection of recombinant human plasminogen activator levels in milk samples using enzyme-linked immunosorbent assay. (A) hemizygous rabbits and (B) homozygous rabbits. rhPA, recombinant human plasminogen activator.

rabbit milk was stabilized at only $0.465 \mathrm{mg} / \mathrm{ml}$ in the first 5 days of the lactation period (Fig. 4).

Activity assay of rhPA in the milk of transgenic rabbits. FAPA was conducted to determine the thrombolytic activity of rhPA, which was measured according to the size of the thrombolytic transparent circle. Activity analysis demonstrated that the rhPA products expressed by the K29 strain of transgenic rabbits exhibited a fibrinolytic activity in vitro (Fig. 5). The rhPA activity in samples was calculated using regression equations of the standard curves (data not shown) based on their transparent diameter size of the thrombin-dissolving ring. Based on the standard curve, the calculated activity of the expressed rhPA in the milk of transgenic rabbits was approximately equivalent to the effects of alteplase (Tables I and II). FAPA also revealed that the proteins from the rhPA homozygote transgenic rabbits had a thrombolytic activity in vitro, and that their specific activity (biological activity/expression level) was $0.12 \times 1,000 \mathrm{mg} / \mathrm{ml}$, which was 2.7-fold higher compared with that of hemizygote rabbits $(0.36 \times 1,000 \mathrm{mg} / \mathrm{ml})$ (Fig. 6). These results demonstrated that the in vitro activity of rhPA in the milk of transgenic rabbits was 110-360-fold higher in comparison with that of the alteplase positive control group.

Analysis of rhPA expression in the milk of transgenic rabbits by western blot analysis. Western blot analysis was also performed to determine the rhPA levels in the different groups. The rhPA protein is shown as two bands with molecular weight of 39 and $37 \mathrm{kDa}$ in SDS-PAGE gels (Fig. 7), which is in accordance with the observations of a previous study (38). Lane 8 represents the protein Marker (SN123, Nanjing Shengxing Biology Company, Nanjing, China), Lanes 2 and 5 are reteplase National Institute for Biological Standards and Control, 20 and $1 \mu \mathrm{g}$, respectively. Lanes 3 and 6 are hemizygous rabbit milk (40 and $80 \mu 1$ purified rabbit milk, respectively). Lanes 4 and 7 are homozygous rabbit milk (40 and $80 \mu \mathrm{l}$ purified rabbit milk, respectively). These results demonstrated that rhPA 
Table I. Enzyme-linked immunosorbent assay of rhPA level in the milk samples.

\begin{tabular}{lrc}
\hline Sample & $\begin{array}{r}\text { rhPA concentration } \\
(\mathrm{ng} / \mathrm{ml})\end{array}$ & $\begin{array}{r}\text { Optical density } \\
\text { at } 450 \mathrm{~nm}\end{array}$ \\
\hline $\begin{array}{l}\text { 1 (non-transgenic } \\
\text { rabbit) }\end{array}$ & 0 & 0 \\
2 & 5 & 0.125 \\
3 & 10 & 0.208 \\
4 & 50 & 0.267 \\
5 & 500 & 0.891 \\
6 & 1,000 & 1.112 \\
7 & 2,000 & 1.245 \\
8 & 4,000 & 1.360 \\
Homozygote K29 & 950 & 1.09 \\
Hemizygote K29 & 465 & 0.86 \\
Hemizygote K29 & 7 & 0.15 \\
\hline
\end{tabular}

rhPA, recombinant human plasminogen activator.

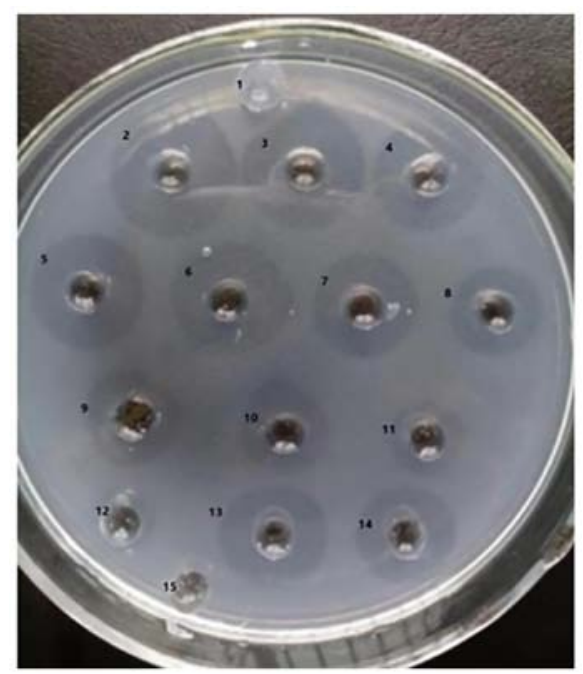

Figure 5. Fibrin agarose plate assay of partial transgenic rabbit whey. Sample 1, PBS; samples 2-12, alteplase serving as an injection standard, at concentrations of $3,000,1,500,750,350,150,70,15,10,5,2$ and $1 \mu \mathrm{g} / \mathrm{ml}$, respectively; sample 13, whey from homozygote K29 transgenic rabbits (diluted to 1,000-fold); sample 14, whey from hemizygote K29 transgenic rabbits (diluted to 1,000-fold); sample 15 , whey from normal nontransgenic rabbits.

homozygote transgenic rabbits were successfully generated and efficiently expressed rhPA.

\section{Discussion}

To the best of our knowledge, the present study is the first to report the expression level and stability of rhPA in the milk produced by homozygote transgenic rabbits (4). A novel PCL25/rhPA transgenic rabbit strain (K29) was established, and high expression levels of rhPA was achieved in the homozygous transgenic rabbit $(5,6)$. Homozygous animals exhibit increased advantages, such as higher genetic stability and no need for transgenic detection of offspring rabbits. Thus, the
Table II. Specific activity of rhPA in the milk samples.

\begin{tabular}{lcc}
\hline Sample & $\begin{array}{c}\text { rhPA concentration } \\
(\mu \mathrm{g} / \mathrm{ml})\end{array}$ & $\begin{array}{c}\text { Transparent circle } \\
\text { diameter }(\mathrm{mm})\end{array}$ \\
\hline $\begin{array}{l}\text { (non-transgenic } \\
\text { rabbit) }\end{array}$ & 0 & 0 \\
2 & 3,000 & 31.5 \\
3 & 1,500 & 28.5 \\
4 & 750 & 25.0 \\
5 & 350 & 23.0 \\
6 & 150 & 21 \\
7 & 70 & 19.5 \\
8 & 15 & 18.0 \\
9 & 10 & 17.5 \\
10 & 5 & 16.0 \\
11 & 2 & 10.0 \\
12 & 1 & 5.0 \\
Homozygote & 320 & 22.5 \\
Hemizygote & 120 & 20.5 \\
\hline
\end{tabular}

rhPA, recombinant human plasminogen activator.

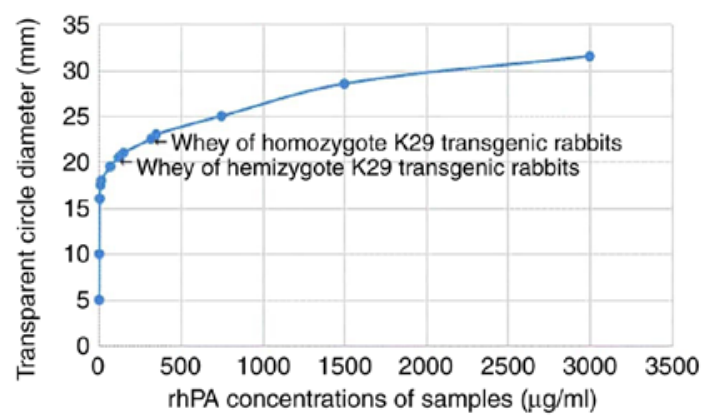

Figure 6. Fibrin agarose plate assay of rhPA concentration in partial transgenic rabbit whey. rhPA, recombinant human plasminogen activator.

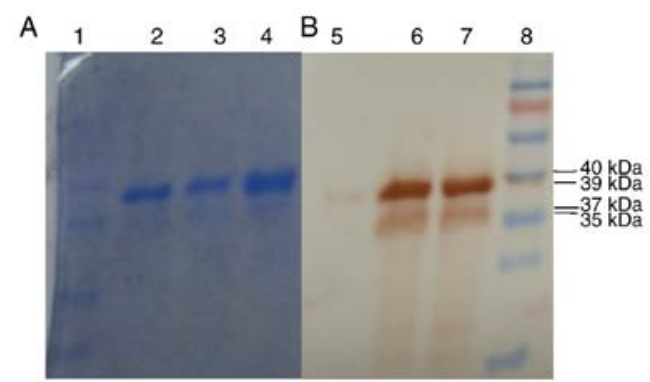

Figure 7. (A and B) SDS-PAGE and western blot analysis of partial K29 strains of rhPA transgenic rabbits. Lane 1, whey of normal nontransgenic rabbits (40 $\mu 1)$; lane 2, whey of hemizygote transgenic rabbits (20 $\mu 1)$; lane 3 , whey of homozygote transgenic rabbits $(10 \mu 1)$; lane 4 , protein marker.

cost may be markedly reduced, and higher levels of rhPA can be obtained in the milk $(24,25)$.

In the present study, individual K29 rabbits with relatively high rhPA expression level were screened out, and homozygous K29 F2 rabbits were generated. ELISA results revealed that 
rhPA expression in homozygous K29 F2 transgenic rabbits exhibited increased levels and stability compared with those in hemizygous K29 strain rabbits. FAPA results also demonstrated that the rhPA expression levels in homozygous K29 F2 transgenic rabbits were 2.7-fold higher in comparison with that in hemizygous K29 strain rabbits. This result was not consistent with the ELISA results, possibly due to the presence of certain substances in the milk that influenced the FAPA results.

Transgenic rabbits were generated in the current study by microinjection, and the exogenous gene was randomly integrated into the animal genome. However, controlling the integration loci and copy number is difficult at present. Due to different integration sites, this may create various transgenic exogenous gene loci, and influence the rhPA expression level and stability $(1-4,39,40)$. Based on the findings in a previous study, the rhPA levels that individual transgenic rabbits expressed were evidently different (5). There are three reasons for this finding: Firstly, the expression of foreign genes and the copy number are correlated. The integration gene copy number of homozygous transgenic rabbits was more than double compared with that of hemizygous transgenic rabbits, which resulted in increased and stable expression. Secondly, a PCL25/rhPA expression vector was built containing enhancer regulation components, which can lead to raised expression. Finally, in the present study, only one gene integration loci site was obtained from the homozygous transgenic rabbit milk sample, and the sample size was small; therefore, more gene integration loci in transgenic rabbits should be investigated in order to examine rhPA expression in the milk of homozygous transgenic rabbits.

It has been reported that other strains of homozygous transgenic rabbits are unable to express rhPA or other recombinant proteins efficiently or stably, while certain studies have also indicated that use of the same recombinant protein and expression vector in different animals resulted in different expression levels (1-4). This may be due to the vector construction or locus, or the different recombinant proteins influencing the expression level or stability (1-4). Therefore, future studies should examine how to control the locus and construct an efficient expression vector in transgenic animals, and how to select expression vectors for specific recombinant proteins, eventually identifying an ideal expression vector and animal species to express different recombinant proteins. The yield must also be further improved by optimization of the expression vector construction or other methods (1-4,39-43).

rhPA expression in the milk of homozygous transgenic rabbits has not been previously reported. The main reason for the use of transgenic rabbits is that surgery in rabbits is simple, the mating period is short, their lactation amount is large, and finally rhPA in the milk is easily purified due to the simple ingredients contained in their milk $(26,27)$. Thus, the present study used transgenic animals as a mammary gland bioreactor to produce recombinant proteins. The present study may provide reference for the large-scale production of recombinant proteins. High rhPA expression through microinjection to generate rhPA transgenic rabbits was conducted in the present study. The results revealed that the exogenous genes in the genome of rabbits can be stably expressed, while also proving that homozygous transgenic animals can feasibly improve foreign gene expression levels and stability in the animal mammalian gland. The present study generated a homozygous rhPA rabbit strain and provided a reliable basis for large-scale production of thrombolytic drugs in the future (6).

In conclusion, the present study constructed homozygous transgenic rabbits with a high expression of rhPA during the entire lactation period. The results of ELISA indicated that the rhPA expression level in homozygous K29 rabbits was markedly higher as compared with that in hemizygous transgenic rabbits. Furthermore, it was verified that improving the expression level of foreign genes is feasible by cultivating homozygous transgenic animals. The current study provided an experimental basis and guidance for establishing a new strain of rhPA homozygous transgenic rabbits, and may find applications in the large-scale preparation of thrombolytic agents.

\section{Acknowledgements}

Not applicable

\section{Funding}

Financial support was provided by the National Key Research and Development Program of China (grant no. 2016YFE0126000) and A Project Funded by the Priority Academic Program Development of Jiangsu Higher Education Institutions.

\section{Availability of data and materials}

All data generated or analyzed during this study are included in this published article.

\section{Authors' contributions}

$\mathrm{ZH}$ and $\mathrm{YC}$ designed the experiments, $\mathrm{ZH}, \mathrm{LJ}, \mathrm{TZ}$ and $\mathrm{MZ}$ performed the experiments. DW, TY and YY analyzed data. YC wrote the manuscript. All authors read the manuscript.

\section{Ethics approval and consent to participate}

The present study was approved by the Institutional Animal Care and Use Committee of Yangzhou University (Yangzhou, China) and was performed according to the Guide for the Care and Use of Laboratory Animals.

\section{Patient consent for publication}

Not applicable.

\section{Competing interests}

The authors declare no conflict of interest.

\section{References}

1. Wang Y, Zhao S, Bai L, Fan J and Liu E: Expression systems and species used for transgenic animal bioreactors. Biomed Res Int 2013: 580463, 2013.

2. Echelard Y., Williams JL, Destrempes MM, Koster JA, Overton SA, Pollock DP, Rapiejko KT, Behboodi E, Masiello NC, Gavin WG, et al: Production of recombinant albumin by a herd of cloned transgenic cattle. Transgenic Res 18: 361-376, 2009. 
3. Dyck MK, Lacroix D, Pothier F and Sirard MA: Making recombinant proteins in animals-different systems, different applications. Trends Biotechnol 21 394-399, 2003.

4. Khodarovicha YM, Goldman IL, Sadchikova ER and Georgiev PG: Expression of eukaryotic recombinant proteins and deriving them from the milk of transgenic animals. ISSN 00036838, Appl Biochem Microbiol 49: 711-722, 2013.

5. Song S, Ge X, Cheng Y, Lu R, Zhang T, Yu B, Ji X, Qi Z, Rong Y, Yuan Y and Cheng Y: High-level expression of a novel recombinant human plasminogen activator (rhPA) in the milk of transgenic rabbits and its thrombolytic bioactivity in vitro. Mol Biol Rep 43: 775-783, 2016.

6. Song S, He Z, Mei J, Qi Z, Chen S, Xu S, Yuan Y and Cheng Y: Affinity purification of recombinant human plasminogen activator from transgenic rabbit milk using a novel polyol responsive monoclonal antibody. Trop J Pharm Res 15: 905-911, 2016.

7. Meunier JM, Wenker E, Lindsell CJ and Shaw GJ: Individual lytic efficacy of recombinant tissue plasminogen activator in an in vitro human clot model: Rate of 'nonresponse'. Acad Emerg Med 20: 449-455, 2013.

8. Bosze Z, Baranyi M and Whitelaw CB: Producing recombinant human milk proteins in the milk of livestock species. Adv Exp Med Biol 606: 357-393, 2008.

9. Chevreux G, Faid V, Scohyers JM and Bihoreau N: $\mathrm{N}$-/O-glycosylation analysis of human FVIIa produced in the milk of transgenic rabbits. Glycobiology 23: 1531-1546, 2013.

10. Gil GC, Velander WH and Van Cott KE: Analysis of the Nglycans of recombinant human factor IX purified from transgenic pig milk. Glycobiology 7: 526-539, 2008.

11. Koles K, van Berkel PH, Pieper FR, Nuijens JH, Mannesse ML, Vliegenthart JF and Kamerling JP: N- and O-glycans of recombinant human $\mathrm{C} 1$ inhibit or expressed in the milk of transgenic rabbits. Glycobiology 14: 51-64, 2004.

12. Zhang YL, Wan YJ, Wang ZY, Xu D, Pang XS, Meng L, Wang LH, Zhong BS and Wang F: Production of dairy goat embryos, by nuclear transfer, transgenic for human acid Bglucosidase. Theriogenology 73: 681-690, 2010.

13. Gordon $\mathrm{K}$ and Groet $\mathrm{S}$ : Transgenic animals secreting desired proteins into milk. King George Holdings Luxembourg Iia S.A.R.L, 2011. US Patent US7939317. Filed February 20, 1992; issued May 10, 2011.

14. Lian LF, Xu F, Tang ZP, Xue Z, Liang QM, Hu Q, Zhu WH, Kang HC, Liu XY, Wang FR and Zhu SQ: Intra clot recombinant tissuetype plasminogen activator reduces perihematomal edema and mortality in patients with spontaneous intracerebral hemorrhage. J Huazhong Univ Sci Technolog Med Sci 34 165-171, 2014.

15. Dotan A, Kaiserman I, Kremer I, Ehrlich R and Bahar I: Intracameral recombinant tissue plasminogen activator (r-tPA)for refractory toxic anterior segment syndrome. Br J Ophthalmol 98: 252-255, 2014

16. Wardlaw JM, Murray V, Berge E, del Zoppo G, Sandercock P, Lindley RL and Cohen G: Recombinant tissue plasminogen activator for acute ischaemic stroke: an updated systematic review and meta-analysis Lancet 379: 2364-2372, 2012.

17. Fonarow GC, Zhao X, Smith EE, Saver JL, Reeves MJ, Bhatt DL, Xian Y, Hernandez AF, Peterson ED and Schwamm LH: Door-to-needle times for tissue plasminogen activator administration and clinical outcomes in acute ischemic stroke before and after a quality improvement $t$ initiative. JAMA 311: 1632-1640, 2014

18. Meyer MW, Witt AR, Krishnan LK, Yokota M, Roszkowski MJ, Rudney JD and Herzberg MC: Therapeutic advantage of recombinant human plasminogen activator in endocarditis: evidence from experiments in rabbits. Thromb Haemost 73: 680-682, 1995.

19. Smalling RW, Bode C, Kalbfleisch J, Sen S, Limbourg P, Forycki F, Habib G, Feldman R, Hohnloser S and Seals A: More rapid, complete, and stable coronary thrombolysis with bolus administration of reteplase compared with alteplase infusion in acute myocardial infarction. Circulation 91: 2725-2732, 1995.

20. Aghaabdollahian S, Rabbani M, Ghaedi K and Sadeghi HM: Molecular cloning of reteplase and its expression in E. coli using tac promoter. Adv Biomed Res 3: 190, 2014.

21. Hong-Ying S, Si-Guo L, Jian-Quan C, Ai-Min Z and Guo-Xiang C: Expression of a variant of human tissue-type plasminogen activator in transgenic mouse milk. J Exp Anim Sci 43: 211-218, 2006.

22. Lijnen HR and Collen D: Strategies for the improvement of thrombolytic agents. Thromb Haemost 66: 88-110, 1991.

23. Davami F, Sardari S, Majidzadeh-A K, Hemayatkar M,BarkhrdariF, Omidi M, Azami M, Adeli A, Davoudi N and Mahboudi F: Expression of a novel chimeric truncated t-PA in CHO cells based on in silico experiments. J Biomed Biotechnol 2010: 108159, 2010.
24. Takezawa J, Yamada K, Miyachi M, Morita A, Aiba N, Sasaki S, Watanabe S and Saku Control Obesity Program (SCOP) Study Group: Preproghrelin gene polymorphisms in obese Japanese women. Minor homozygotes are light eaters, do not prefer protein or fat, and apparently have a poor appetite. Appetite 63: 105-111, 2013.

25. Knox-Macaulay HH, Rehman JU, Al Zadjali S, Fawaz NA and Al Kindi S: Idiopathic thrombocytopenic purpura and hypokalaemic dRTA with compensated haemolysis and striking acanthocytosis in a band 3 (SLC4A1/AE1) A858D homozygote. Ann Hematol 92: 553-554, 2013.

26. Xue F, Ma Y, Chen YE, Zhang J, Lin TA, Chen CH, Lin WW, Roach M, Ju JC, Yang L, Du F and Xu J: Recombinant rabbit leukemia inhibitory factor and rabbit embryonic fibroblasts support the derivation and maintenance of rabbit embryonic stemb cells. Cell Reprogram 14: 364-376, 2012.

27. Fan $\mathrm{J}$ and Watanabe T: Transgenic rabbits as therapeutic protein bioreactors and human disease models. Pharmacol Ther 99: $261-282,2003$

28. Goldman IL, Georgieva SG, Gurskiy YG, Krasnov CA, Deykin CA, Popov AN, Ermolkevich TG, Budzevich AI, Chernousov AD and Sadchikova ER: Production of human lactoferrin in animal milk. Biochem Cell Biol 90: 513-519, 2012.

29. Pollock DP, Kutzko JP, Birck-Wilson E, Williams JL, Echelard Y and Meade HM: Transgenic milk as a method for the production of recombinant antibodies. J Immunol Methods 231: 147-157, 1999.

30. Zhou Q, Kyazike J, Echelard Y, Meade HM, Higgins E, Cole ES and Edmunds T: Effect of genetic background on glycosylation heterogeneity in human antithrombin produced in the mammary gland of transgenic goats. J Biotechnol 117: 57-72, 2005.

31. Granelli-Piperno A and Reich E: A study of proteases and protease-inhibitor complexes in biological fluids. J Exp Med 148: 223-234, 1978.

32. Bayne K: Developing guidelines on the care and use of animals. Ann N Y Acad Sci 862: 105-110, 1998.

33. Denman J, Hayes M, O'Day C, Edmunds T, Bartlett C, Hirani S, Ebert KM, Gordon K and McPherson JM: Transgenic expression of a variant of human tissue-type plasminogen activator in goat milk: Purification and characterization of the recombinant enzyme. Biotechnology 9: 839-843, 1991.

34. Parker MH, Birck-Wilson E, Allard G, Masiello N, Day M, Murphy KP, Paragas V, Silver S and Moody MD: Purification and characterization of a recombinant vers ion of human A-feto protein expressed in the milk of transgenic goats. Protein Expr Purif 38: 177-183, 2004.

35. Kim HJ: Glycosylation variant analysis of recombinant human tissue plasminogen activator produced in urea-cycleenzyme-expressing Chinese hamster ovary (CHO) cell line. J Biosci Bioeng 102: 447-451, 2006.

36. Farid SS: Process economics of industrial monoclonal antibody manufacture. J Chromatogr B Analyt Technol Biomed Life Sci 848: 8-18, 2007.

37. Barrett AJ, Rawlings $\mathrm{N}$ and Woessner J (eds): E-STREAMS: Electronic Reviews of Science and Technology. In: Handbook of proteolytic enzymes. 2nd edition. Elsevier, Amsterdam, 2946-2952, 2004.

38. Kwon JY, Yang YS, Cheon SH, Nam HJ, Jin GH and Kim DI: Bioreactor engineering using disposable technology for enhanced production of hCTLA4Ig intransgenic rice cell cultures. Biotechnol Bioeng 110: 2412-2424, 2013.

39. Rader RA: Expression systems for process and product improvement. BioProcess Int 66 (Suppl 4): S4-S9, 2008. http:// www.bioprocessintl.com/w p-content/uploads/2014/05/ BPI_A_080606SUPAR01_78704a.pdf.

40. Ryll T: Antibody production using mammalian cell culture-how high can we push productivity. SIM annual meeting program \& abstract. San Diego S146, 2008.

41. Luo Y, Wang Y, Liu J, Lan H, Shao M, Yu Y, Quan F and Zhang Y: Production of transgenic cattle highly expressing human serum albumin in milk by phiC31 integrase-mediated gene delivery. Transgenic Res 24: 875-883, 2015.

42. Zhou Y, Lin Y, Wu X, Xiong F, Lv Y, Zheng T, Huang P and Chen $\mathrm{H}$ : The high-level expression of human tissue plasminogen activator in the milk of transgenic mice with hybrid gene locus strategy. Mol Biotechnol 50: 137-144, 2012.

43. Fujiwara Y, Miwa M, Takahashi R, Hirabayashi M, Suzuki T and Ueda M: Position-independent and high-level expression of human alpha-lactalbumin in the milk of transgenic rats carrying a 210-kb YAC DNA. Mol Reprod Dev 47: 157-163, 1997. 